NBER WORKING PAPER SERIES

COMMODITY PRICES AS A LEADING INDICATOR OF INFLATION

James M. Boughton

William H. Branson

Working Paper No. 2750

\author{
NATIONAL BUREAU OF ECONOMIC RESEARCH \\ 1050 Massachusetts Avenue \\ Cambridge, MA 02138 \\ October 1988
}

Mr. Branson's work on this paper was completed in part while he was a Visiting Scholar at the IMF, and in part while a Visiting Scholar at the Banca d'Italia. We are grateful to Tom Walter, who carried out the empirical tests for this paper; to a number of colleagues at the IMF, especially Blair Rourke and Alphecca Muttardy, who helped prepare and interpret the data; to Mark Watson for a number of suggestions; and to particlpants at seminars at the IMF and the Banca d'Italia. The views expressed herein are those of the authors and should not be attributed to any institution. 
NBER Working Paper \#2750

October 1988

\title{
COMMODITY PRICES AS A LEADING INDICATOR OF INFLATION
}

\author{
ABSTRACT
}

This paper studies the value of broad commodity price indexes as predictors of consumer price inflation in the G-7 industrial countries. After an introduction, the paper discusses the theoretical relationship between commodity and consumer prices and the conditions under which, in general, one would expect commodity prices to be a leading indicator of inflation. It then presents tests of the relationships between conventional broad indexes of commodity prices and consumer prices, and uses the data on individual commodities to generate the optimum weights in a commodity price index for forecasting G-7 inflation. We find that commodity and consumer prices are not co-integrated; the hypothesis that there is a reliable long-run relationship between the level of commodity prices and the level of consumer prices may be rejected. There is a tendency for changes in commodity prices to lead those in consumer prices, at least when the data are denominated in a broad index of major-country currencies. However, although the inclusion of commodity prices significantly improves the in-sample fit of regressions of an aggregate (multi-country) consumer price index, the results may not be sufficiently stable to improve post-sample forecasts. Estimated alternative commodityprice indexes, in which the weights are chosen so as to minimize the residual variance in aggregate inflation regressions, track the behavior of the aggregate CPI reasonably well in-sample. However, the estimated indexes work only moderately well in post-sample predictions, and they do not appear to offer significant advantages over the conventional exportweighted index. Perhaps the most important result is that turning points in commodity-price inflation frequently precede turning points in consumer-price inflation for the large industrial countries as a group.

James M. Boughton Research Department IMF

Washington, DC 20431
William H. Branson

Woodrow Wilson School

Princeton University

Princeton, NJ 08544 


\section{Introduction}

Changes in commodity prices have long played an important indicative role in analyses of global economic conditions, principally because of their importance for developing countries. More than 70 countries derive at least 50 percent of their export earnings from nonfuel primary commodities; another 20 derive the majority of their export earnings from fuels (see IMF, 1988, PP. 104-105). Changes in the terms of trade for these countries typically arise largely from changes in world commodity prices. Recently, however, attention has also been drawn to the importance of changes in commodity prices as indicators of changes in inflationary conditions affecting industrial countries. For example, the World Economic Outlook recently began to include an analysis comparing percentage changes in an index of 40 primary commodity prices with the aggregate inflation rate of the seven largest industrial countries (see IMF, 1988, p. 11). The task of this paper is to examine the usefulness of commodity prices as a leading indicator of inflation in the large industrial countries as a group.

An early exponent of focusing on commodity prices in this context was Robert Hall. In his 1982 book, Hall argued in favor of basing U.S. monetary policy on a commodity standard, with the commodities chosen on the basis of the closeness of their historical fit against the cost of living. If Bosworth and Lawrence (1982) also emphasized the role of commodity prices as a contributor to the rise in inflationary pressures

1) The index favored by Hall at that time was limited to four commodities: ammonium nitrate, copper, aluminum, and plywood (p. 112). Hall later (1987) emphasized the limitations of that index. 
during the 1970s. More recently, Federal Reserve Board Governor Wayne Angell (1987) noted the close qualitative link between turning points in a broad index of commodity prices and turning points in the U.S. CPI. Others, notably Klein (1986) and Roth (1988), have examined the performance of commodity prices as one component of overall predictions of Inflation.

Chart 1 presents inflation rates for the U.S. CPI and a world export-weighted index of commodity prices; this chart is similar to one presented by Angell. Two stylized facts emerge clearly. First, there is a similarity in the cycles for commodity and consumer prices, with the commodity-price cycles often turning ahead of those in the CPI. Second, the amplitudes of these cycles are very different (note the differences in the two scales). There is thus a presumption that the relationship is more qualitative than quantitative. Chart 2 presents the same type of information except that CPI inflation is a weighted average of inflation rates in the seven largest industrial countries, as in the World Economic outlook. The qualitative relationships are generally similar in the two sets of data. These stylized facts are discussed more critically in the empirical sections that follow.

This paper begins (Section II) by discussing the theoretical relationship between commodity and consumer prices and the conditions under which, in general, one would expect commodity prices to be a leading indicator of inflation. Section III then presents some tests of the relationships between conventional broad indexes of commodity prices and consumer prices. In Section IV, the question of using the data to 
RATES OF CHANGE OF COMMODITY PRICES AND

U.S. CONSUMER PRICES, IN U.S. DOLLARS, 1960-87 ${ }^{1}$

(In percent)
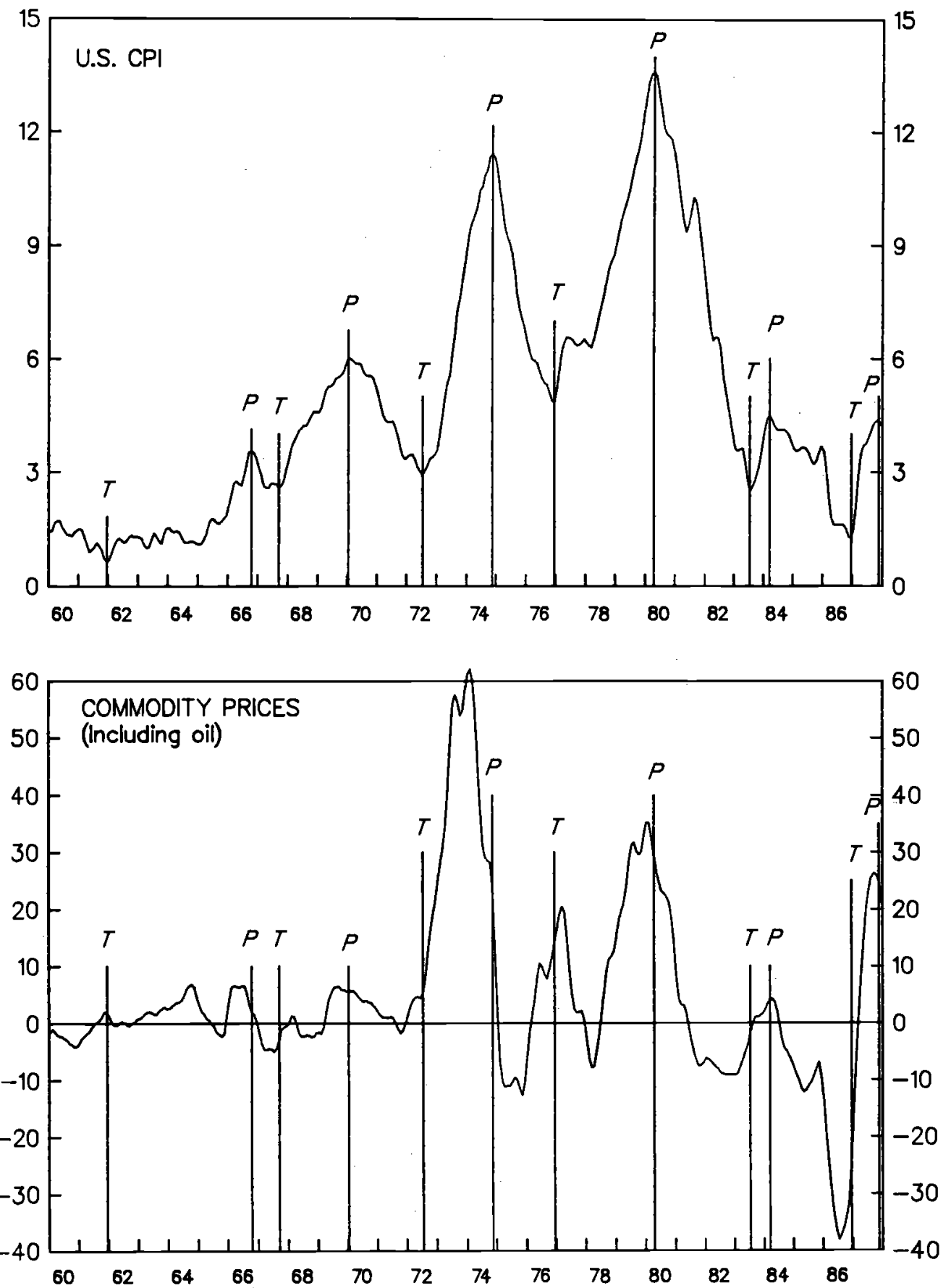

1 Three-month centered moving ovoroge of 12-month inflotlon rates.

$T$ and $P$ denote troughe and peake, respectlvely, In the CPI. 
CHART 2

RATES OF CHANGE OF COMMODITY PRICES AND INDUSTRIALCOUNTRY CONSUMER PRICES, IN AN AGGREGATE CURRENCY BASKET $1960-87^{1}$

(In percent)
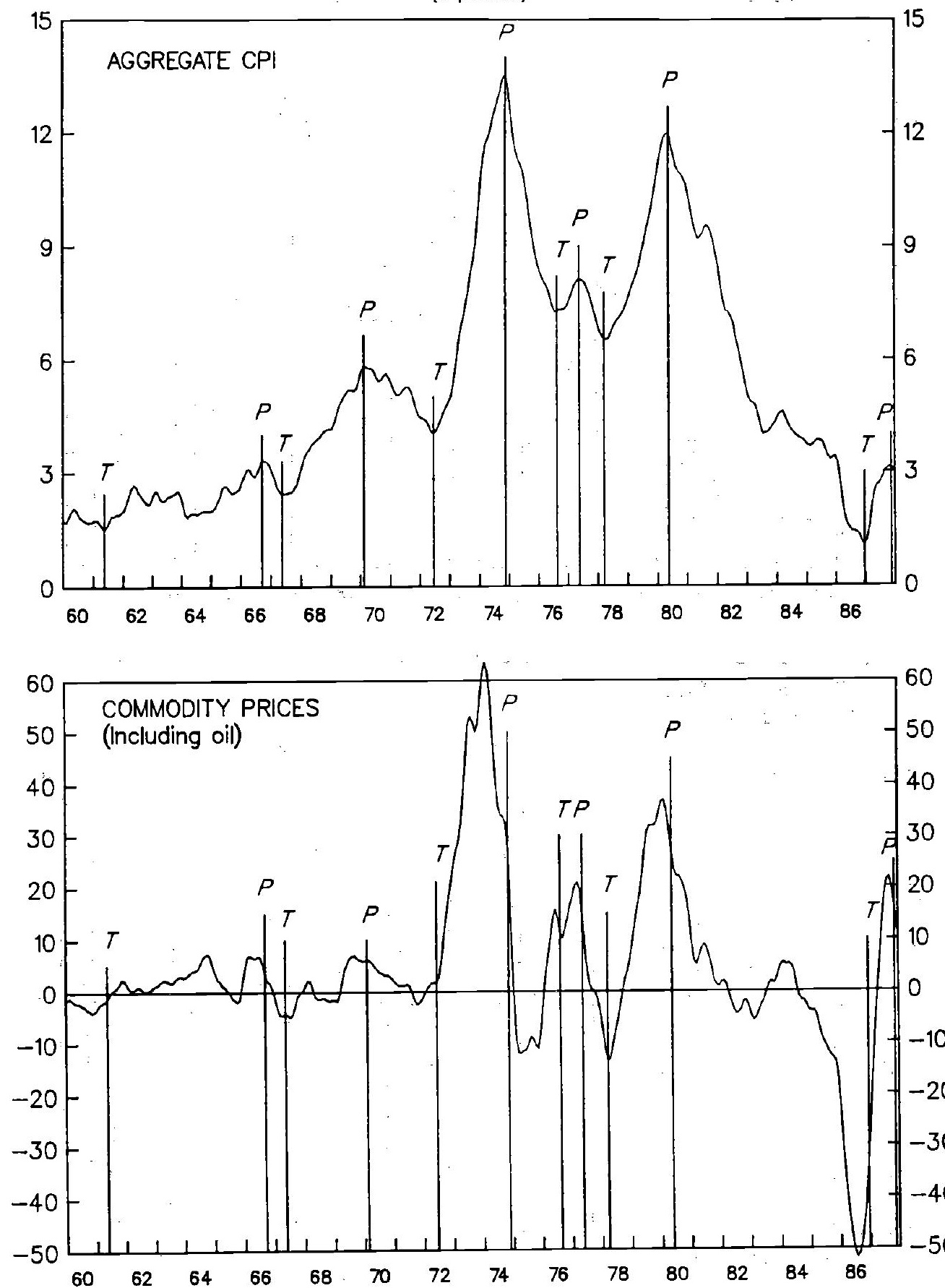

1 Throe-month centered moving average of 12 -month inflation rates.

The $P$ donote troughs and pooks, rospoctively, in the CPI. 
generate the optimum weights in a commodity price index is taken up. Conclusions are summarized in Section $v$.

\section{A Dynamic Model of Commodity and Industrial Prices}

This section presents a dynamic model of the relationship between commodity and industrial prices as a theoretical motivation for the idea of movements in commodity prices as a leading indicator of general price level fluctuations. The model treats commodities as either final goods or inputs, and emphasizes the role of expectations in determining movements of commodity prices.

An important feature of the model is that commodity prices are determined in "auction" markets, actually financial markets that trade commodity contracts, while industrial prices are set by sellers and adjusted gradually. This permits commodity prices to react immediately to "news" about future inflation, and to lead adjustment of industrial prices. The two cases of commodities as final goods or as inputs are treated separately, but the basic results are the same in both cases. With unanticipated monetary disturbances, commodity prices overshoot and lead industrial prices, but with real disturbances the relationship is less clear. For example, with a supply shock and no monetary accommodation, commodity prices would lead industrial prices, but the two would move in opposite directions.

\section{Commodities as final goods}

This subsection discusses a basic dynamic model of the interaction of commodity and industrial prices in which the two are final goods entering the CPI, and commodity prices are determined in flexible markets 
with forward-looking expectations. The model can be interpreted as one country with two sectors, or as two countries, one producing commodities and the other a perishable industrial output. The model includes a monetary sector, in which expectations of commodity price movements are important, and an industrial sector, in which prices adjust gradually following excess demand. To focus attention on price dynamics, the level of real output in the industrial sector is held constant. The model is an extension of Frankel (1986), which applies the Dornbusch (1976) overshooting model to the case of commodity price dynamics.

Equilibrium in the money market is described in the standard form of equation (1):

(1) $\mathrm{m}-\alpha_{\mathrm{P}_{\mathrm{m}}}-(1-\alpha) \mathrm{P}_{\mathrm{c}}-\phi \mathrm{y}-\lambda i$.

Here m, $P_{m}, P_{c}$, and $y$ are the logarithms of nominal money, the price of manufactures, the price of commodities, and real output; $i$ is the nominal short-term interest rate; and $\alpha$ is the share of manufactures in the CPI. Commodity price inflation and the interest rate are related by an arbitrage condition:

(2) $i-\dot{p}_{c}+b$,

where $\underline{b}$ is the real return to holding commodities for final use, net of storage costs, and $\dot{\mathrm{P}}_{c}$ is the expected rate of change of the commodity price. 
Substitution of equation (2) into (1) yields the first dynamic equation:

(3) $m-a p_{m}-(1-a) p_{c}-\phi y-\lambda\left(\dot{p}_{c}+b\right)$.

The locus of points where $\dot{P}_{c}-0$ is shown in Figure 1 ; its slope is $-(1-\alpha) / \alpha$.

For a point above the $\dot{\mathrm{p}}_{c}=0$ line to be consistent with money market equilibrium, $P_{c}$ must be expected to rise. This is because above the line the CPI is higher, and real balances lower, than on it. This makes the interest rate higher than $\underline{b}$ above the $\dot{\mathrm{p}}_{c}=0$ line, so commodity prices must be expected to rise. If expectations exhibit perfect foresight, $P_{c}$ must actually be rising above the $\dot{\mathrm{P}}_{c}-0$ line. In other words, a commodity price level above that consistent with zero expected inflation must be supported by a positive rate of commodity price inflation. Similarly, at any point below the $\dot{p}_{c}-0$ line, commodity prices would be falling. These dynamics of $P_{c}$ are shown by the horizontal arrows in Figure 1 .

The supply of the industrial good $\left(y_{m}\right)$ is assumed to be constant. Demand is assumed to be an increasing function of the price of commodities relative to industrial goods, $P_{c} / P_{m}$, and a decreasing function of the real interest rate in terms of the industrial good. Thus demand is given by

(4) $d-\delta\left(p_{c}-p_{m}\right)-\sigma\left(i-\dot{p}_{m}\right)$. 
FIGURE 1

COMMODITY AND

MANUFACTURES PRICES: MARKET EQUILIBRIUM AND DYNAMICS

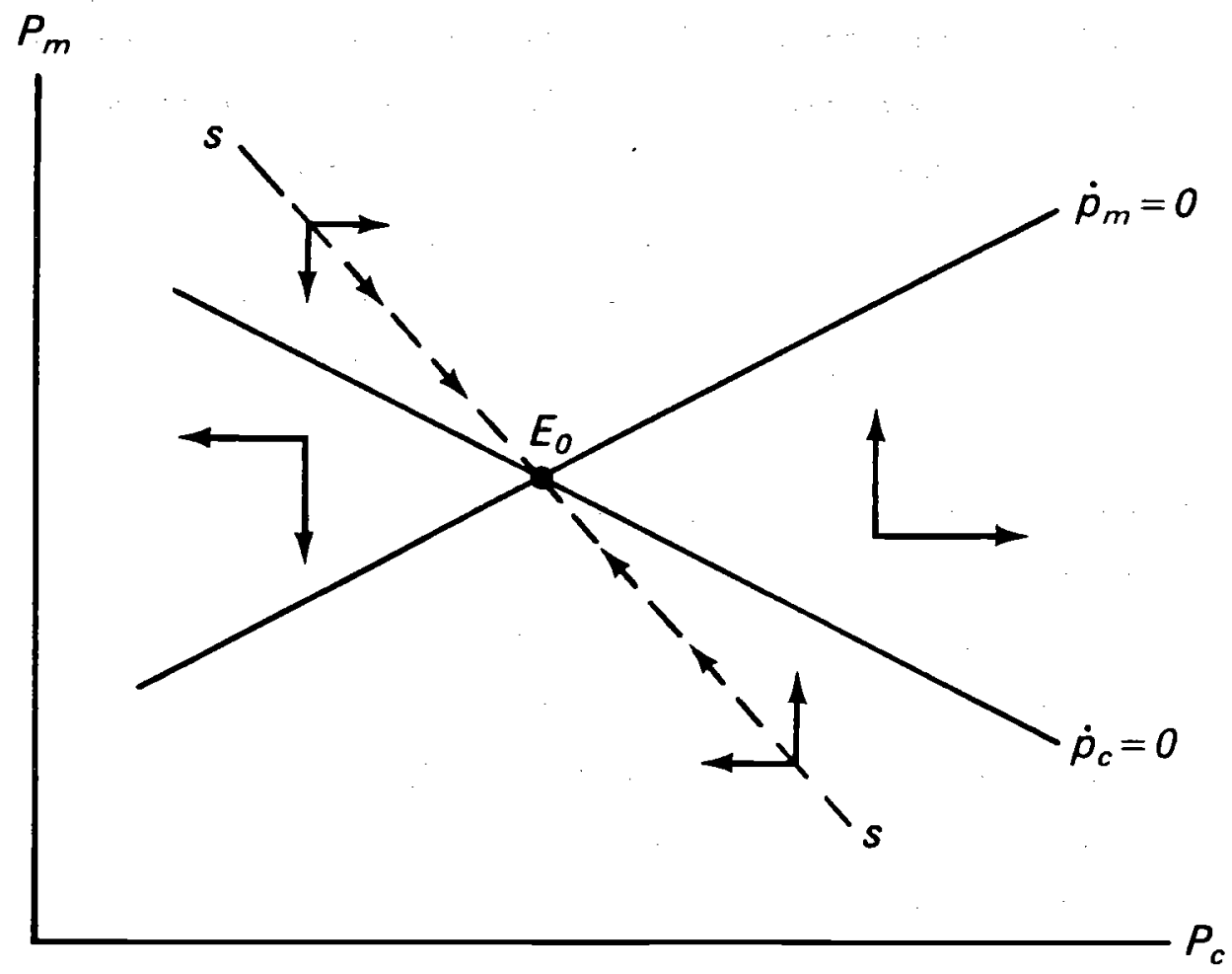


The price of the industrial good is assumed to adjust slowly to eliminate excess demand:

(5) $\dot{\mathrm{P}}_{\mathrm{m}}=\pi\left[\delta\left(\mathrm{P}_{\mathrm{c}}-\mathrm{P}_{\mathrm{m}}\right)-\sigma\left(1-\dot{\mathrm{P}}_{\mathrm{m}}\right)-\mathrm{y}_{\mathrm{m}}\right]$.

The terms on $\dot{\mathrm{P}}_{\mathrm{m}}$ can be consolidated to yield the second dynamic equation:

(6) $\dot{\mathrm{p}}_{\mathrm{m}}-\eta\left[\delta\left(\mathrm{P}_{\mathrm{c}}-\mathrm{P}_{\mathrm{m}}\right)-\sigma i-\mathrm{y}_{\mathrm{m}}\right]$,

where $\eta-\pi /(1-\pi \sigma)$. This term must be positive if a positive shock to excess demand is to raise the price of industrial goods.

The positively sloped $\dot{\mathrm{p}}_{\mathrm{m}}-0$ line in Figure 1 shows the relationship between the two prices that would maintain zero excess demand in the market for industrial goods for a given value of the money stock. The slope of the line is positive because an increase in the commodity price creates excess demand for industrial output, requiring an increase in the industrial price to eliminate it. The slope is less than unity because as prices rise, the interest rate also rises, reducing the demand for industrial goods. I So as the price of commodities rises, the increase in industrial goods prices needed to eliminate excess demand is less than proportional. At points above the $\dot{\mathrm{p}}_{\mathrm{m}}-0$ line, there is excess supply of industrial goods and the price is falling, assuming $\eta>0$. Below the line, there is excess demand and the price is rising. The dynamics of adjustment of the industrial price are summarized by the vertical arrows in Figure 1 .

1 Upward movement along the $\vec{p}_{m}=0$ locus implies $\vec{p}_{c}>0$; from equation (2), this requires a rise in the interest rate. 
The two equilibrium lines in Figure 1 show the equilibrium pair of prices at $E_{0}$ for a given money stock and real commodity supply conditions. The dynamic adjustment to equilibrium is along the stable saddle path ss. This path has two essential properties. It leads to the equilibrium, and along it the expected rate of change of the commodity price is realized. All other paths explode away from the equilibrium; they are speculative bubbles. The assumption that the market seeks out the stable ss path is equivalent to assuming that speculative bubbles are unsustainable. Eventually they collapse, and the market moves back to the stable path.

The model of Figure 1 can be used to illustrate two properties of commodity price behavior that are important for constructing a leading indicator for inflation: following an unanticipated increase in the money supply, commodity prices overshoot, and they lead the adjustment in prices of industrial goods. In a situation in which the signals from the various monetary aggregates are unclear, the movements in commodity prices can be interpreted as distilling the information in the aggregates into a clearer signal.

The role of commodity prices as a leading indicator of the inflationary effects of a monetary disturbance is illustrated in panel (a) of Figure 2, which shows the effects of an unanticipated increase in the money supply. If the model is interpreted as representing two countries, this would involve a proportional increase in both countries' money supplies. The original equilibrium from Figure 1 is at $E_{0}$ in Figure 2. An increase in the money supply shifts both the $\dot{p}_{c}-0$ and $\dot{p}_{m}=0$ lines, and the new long-run equilibrium moves proportionately out to $E_{1}$. In the 
FIGURE 2

PRICE ADJUSTMENTS WITH COMMODITIES AS FINAL GOODS

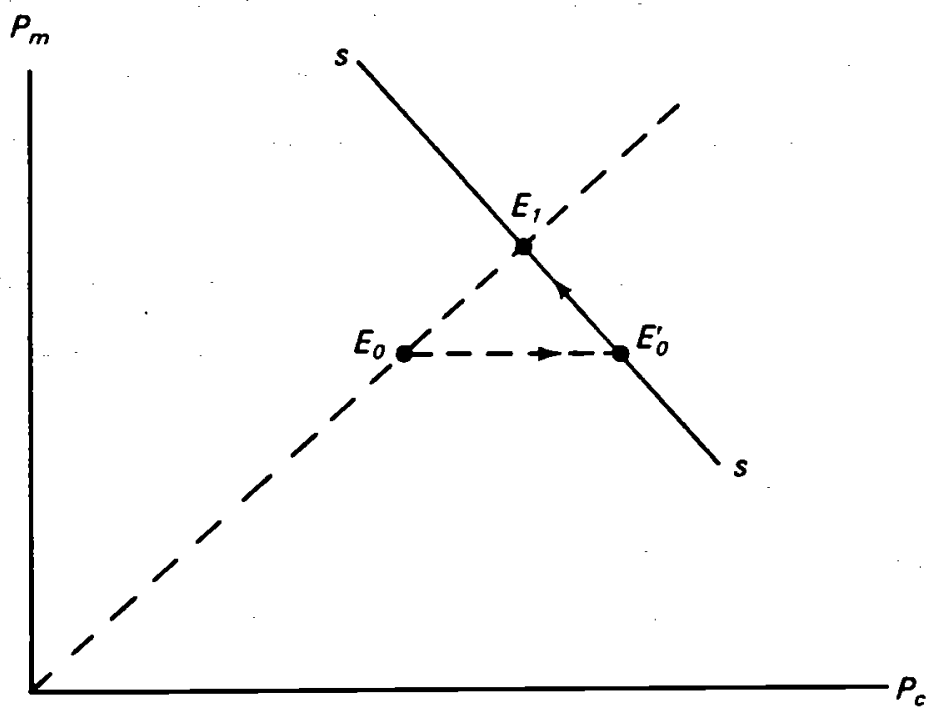

(a) Monetary Disturbance (Overshooting)

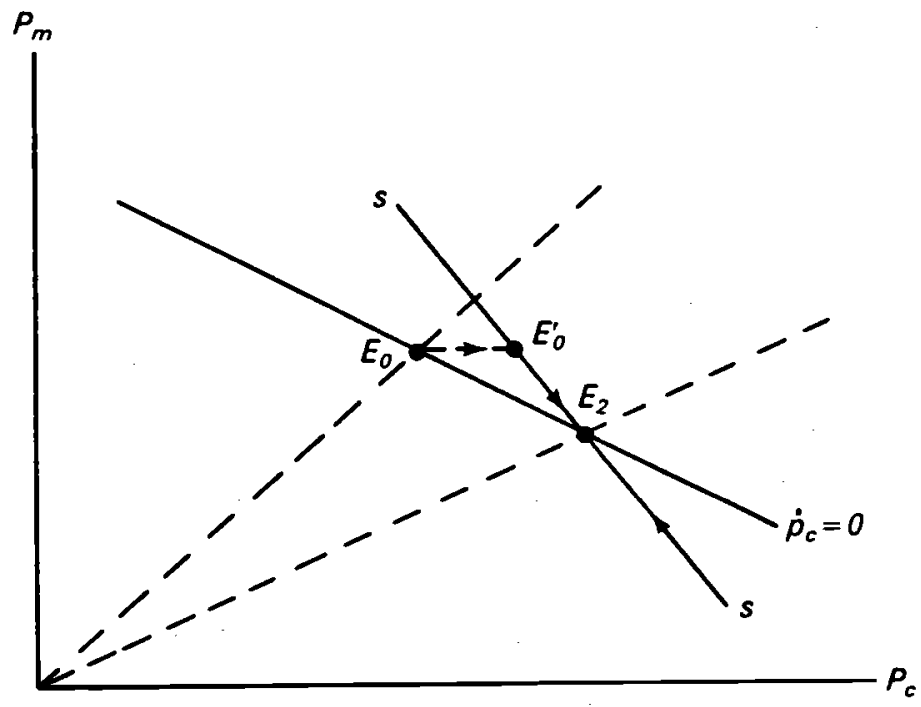

(b) Real Disturbance (Undershooting) 
long run, both prices rise by the same proportion as the money supply. In the short run, the gradually adjusting industrial price does not move, but the flexible commodity price jumps to the new ss path at $E_{0}{ }^{\prime}$. Then gradually the industrial price rises and the commodity price falls along the ss path to the new equilibrium at $E_{1}$.

The initial jump in the commodity price is consistent with an initial decline in the interest rate. In the original equilibrium at $E_{0}$, the expected rate of commodity price increase is zero, and the interest rate is equal to $\underline{b}$. The rise in the money supply increases real balances infially, reducing the interest rate below $\underline{b}$. This is consistent with equilibrium only if commodity prices are expected to fall. So initially the commodity price must rise by enough to create the expectation that it will fall during the adjustment period. This generates the jump onto the new ss path, along which the commodity price falls as expected as the economy moves toward $E_{1}$. At that point, real balances and the interest rate are back to their original levels, and the expected rate of commodity price inflation is again zero.

The reaction of the model to a real disturbance that alters the equilibrium relative price of commodities is shown in panel (b) of Figure 2. As one would expect, it is substantially different from the reaction to a monetary disturbance. Suppose that a supply shock raises the equilibrium relative price of commodities. This shifts the $\dot{\mathrm{P}}_{\mathrm{m}}=0$ line down along the $\dot{\mathrm{P}}_{\mathrm{c}}=0$ line to a new long-run equilibrium at $E_{2}$, which lies on a ray from the origin that characterizes the new higher ratio of commodity prices to industrial prices. With no monetary accommodation, the $\dot{\mathrm{P}}_{c}=0$ line does not move. The result is that 
commodity prices fump onto the new ss path at $E_{0}{ }^{\prime}$ and then continue to rise, gradually, as industrial prices fall toward the new equilibrium $\mathrm{E}_{2}$. As is usual in this type of model, the commodity price undershoots in response to a real disturbance. The industrial price must fall if there is no monetary accommodation. So in this case commodity prices lead, but industrial prices move in the opposite direction.

It appears that commodity prices would not be a reliable indicator of future price developments in the presence of unaccommodated supply shocks, unless reliable information were available about the nature and the effects of those shocks. This problem can be minimized, although probably not eliminated, by using an index of commodity prices that are subject to supply shocks from different, preferably independent, sources. Such an index would resemble a portfolio of commodities with a minimum aggregate variance from supply disturbances, since at any point in time positive and negative disturbances would be offsetting. Presumably movements in this index would be dominated by demand disturbances, actual or expected, which would be a desirable property of an inflation indicator.

\section{Commodities as inputs}

The case of commodities as inputs can be discussed more briefly, since only two minor modifications need to be made to the model, and the results are essentially the same. In the money market, the deflator is now simply the price of industrial goods, so the dynamic equation (3) reduces to

(3') m- $p_{m}-\phi y-\lambda\left(\dot{p}_{c}+b\right)$. 
This change makes the $\dot{p}_{c}-0$ line in the top panel of Figure 3 horizontal at the level of the industrial price that clears the money market with zero expected commodity price inflation. 1 At points above the $\dot{\mathrm{p}}_{c}=0$ line, real balances are lower than on it, so the interest rate is higher than $\underline{b}$, and commodity prices are expected to rise. Below the $\dot{\mathrm{P}}_{\mathrm{c}}=0$ line, commodity prices are falling. These dynamics are illustrated by the horizontal arrows in the top panel of Figure 3.

The market for industrial output is slightly more complicated. The demand for industrial goods is a decreasing function of the real interest rate. The supply of industrial goods is an increasing function of their price relative to commodities. Therefore, excess demand is a decreasing function of the relative price of industrial goods and the real interest rate. This gives a new equation for $\dot{p}_{m}$ :

$\left(6^{\prime}\right) \dot{\mathrm{p}}_{\mathrm{m}}=\eta\left[\beta\left(\mathrm{P}_{\mathrm{c}}-\mathrm{P}_{\mathrm{m}}\right)-\sigma \mathrm{I}\right]$.

Here $\beta$ represents the supply effect, and $\eta$ is defined as before.

The $\dot{\mathrm{p}}_{\mathrm{m}}=0$ locus is the positively sloped line in the top panel of Figure 3. To hold excess demand equal to zero in the market for industrial goods with a given increase in the commodity price, the industrial price would increase less than proportionately because the interest rate rises. Thus, the $\dot{p}_{m}-0$ line along which excess demand for the industrial good is zero has a slope less than unity in the top panel

\footnotetext{
1 Movement to the right along the $\mathrm{p}_{c}=0$ line in Figure 3 implies falling value added in the industrial sector, since input prices are rising against constant output prices. Therefore, if the vertical axis in Figure 3 measured the price of industrial-sector value added instead of the price of final output, the $\dot{p}_{c}=0$ line would be downward-sloping, as before.
} 
FIGURE 3

PRICE ADJUSTMENTS WITH COMMODITIES AS INPUTS

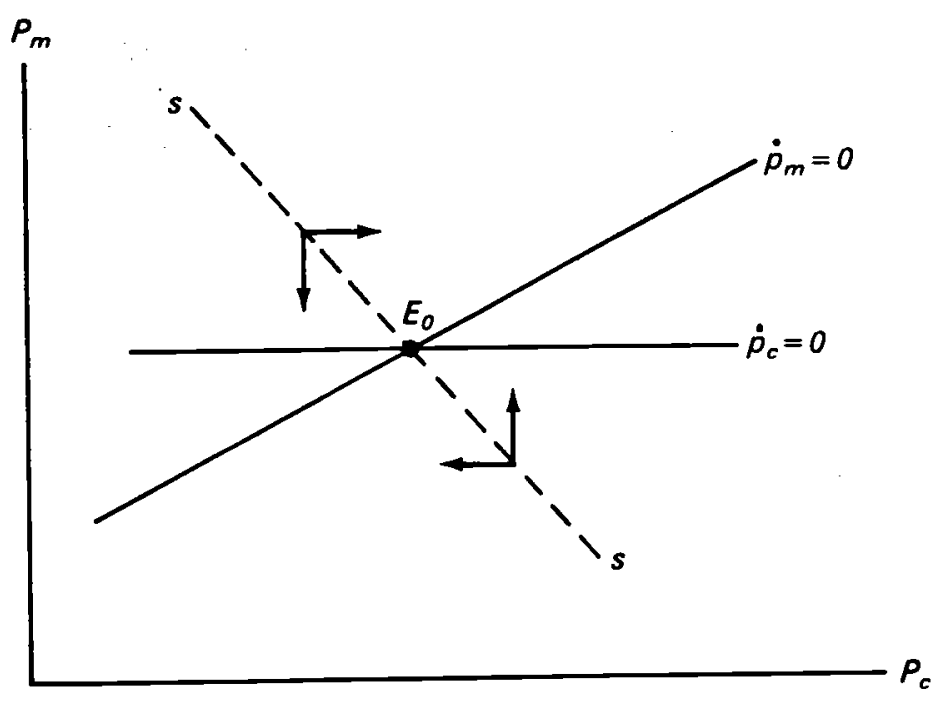

(a) Market Equilibrium

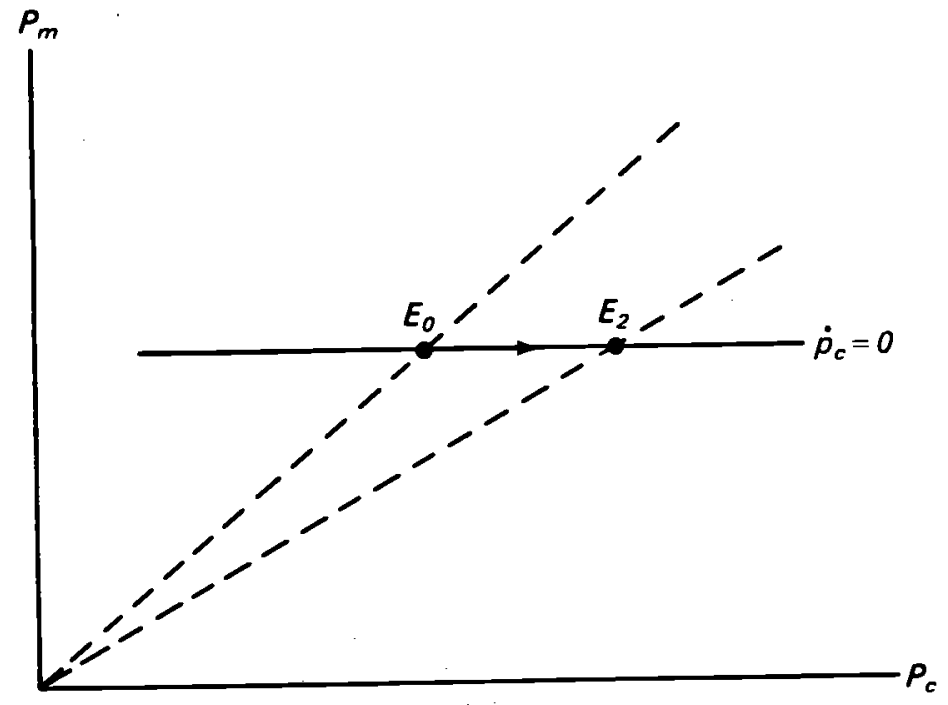

(b) Real Disturbance 
of Figure 3. Above this line, there is excess supply and $P_{m}$ is falling. Below 1t, $P_{m}$ is rising. The stable dynamic adjustment path is $s s$ in Figure 3 , as in the case of commodities as final goods.

The analysis following an unanticipated increase in the money supply is the same as that in panel (a) of Figure 2, discussed above. Adjustment to a supply shock that raises the equilibrium price of commodities relative to that of industrial output is illustrated in the bottom panel of Figure 3. The $\dot{\mathrm{P}}_{\mathrm{m}}=0$ line shifts out to intersect the $\dot{\mathrm{P}}_{c}=0$ line at the new equilibrium price ratio. The commodity price rises, but, with no monetary accommodation, the price of industrial goods remains unchanged. The price of value added in the industrial sector or country falls. As before, it may be noted that a broad index of commodity prices might essentially average out supply shocks, leaving monetary disturbances to dominate movements of the index.

In these two models, commodity prices play the role of an inflation hedge. With gradual adjustment of Industrial prices, agents can protect themselves against an anticipated inflation by buying commodities or, more generally, commodity futures contracts. The result falls naturally out of an analysis with two prices, one that adjusts gradually and one that can jump. The latter becomes the hedge against inflation in the former. A rlcher model would include more prices, such as foreign exchange or domestic equities, that can adjust instantaneously to inflationary expectations. In such a model, several variables can play the role of inflation hedge, with a wide variety of over-shooting and under-shooting behavior. This was shown in Frenkel and Rodriguez (1982) Then which price is the best indicator of future inflation becomes an 
empirical question. The conclusion to be drawn from the analysis in this section is that commodity prices are a reasonable candidate.

\section{Empirical Tests Using Conventional Indexes}

This section evaluates the empirical relationships between commodity prices and general price movements in industrial countries. In order to simplify the discussion, tests will be presented only for consumer rather than output prices as the objective variable, and only for the large industrial countries as a group. 1/ These decisions are somewhat arbitrary, but there is likely to be a stronger empirical link from commodity prices to consumer prices than to output prices, especially in countries that are net importers of primary commodities. Focusing on the aggregate inflation rate for a broad group of countries may also enhance the measured importance of commodity prices as a leading indicator; changes in inflation in individual countries may be relatively more affected by policy actions and exogenous domestic events and less by international variables.

\section{Construction of data}

The first empirical task is to construct a data series for the aggregate CPI for the large industrial countries. How best to do this is not obvious, because national price data are in different currencies. One approach would be to convert the time series data on price levels Into a common currency (say, U.S. dollars or SDRs) and then construct an average index using GNP, consumption, or some other set of weights. One

1 The countries are the United States, Japan, the Federal Republic of Germany, France, the United Kingdom, Italy, and Canada. 
would then have a direct estimate of the aggregate price level measured in that currency. An alternative would be to average the logarithms of the price levels in local-currency terms. This procedure would give a more accurate measure of the average inflation experience in the countries concerned. Which procedure to choose depends on the intended purpose, but in the present case the choice is complicated because of the diverse international structure of the markets for primary commodities.

The problem may be illustrated as follows. If the national price indexes are averaged directly, the aggregate price level is described by

(7) $p_{t}=\sum_{i=1}^{7} w_{i} p_{i, t}$

where $\mathrm{p}$ is the logarithm of the aggregate CPI, $\mathrm{p}_{i}$ is the logarithm of the CPI for country $\underline{i}$ (denominated in the currency of that country), and the $w_{i}$ are the weights. Alternatively, if the aggregate CPI is to be denominated in the currency of (say) the first country, then the formula may be written as

(7') $p_{t}^{\prime}=w_{i} p_{1, t}+\sum_{i=2}^{7} w_{i}\left(e_{i, t}+p_{i, t}\right)$

where $e_{i}$ is the logarithm of the exchange rate for country $\underline{i}$, expressed as the cost of local currency in terms of the currency of country 1 .

The difference between these two measures of the aggregate CPI constitutes an exchange rate between the currency of country 1 and the 
weighted geometric average of the other countries as a group:

(8) $p_{t}^{\prime}-p_{t}=\sum_{i=2}^{7} w_{i} e_{i, t}=e_{t}$

For the tests in this paper, the aggregate CPI is constructed according to equation (7); for convenience, the implicit currency basket in which the data are thereby denominated will be referred to as the "group currency unit" or GCU. 1

The difficulty posed by this choice is that the relationship between commodity and consumer prices is not invariant with respect to the currency in which the data are denominated. In order to isolate the effects of commodity price movements on inflation from those of exchange rate changes, it is desirable not only that commodity and consumer prices be denominated in the same currency or basket, but also that that denomination correspond as closely as possible to the currency or basket that is most relevant for the various markets concerned. This last concept, however, is quite vague and difficult to judge empirically. Most commodity prices are quoted in U.S. dollars, but a number of them are quoted in other currencies, including notably pounds sterling, deutsche marks, and Japanese yen. Furthermore, the currency in which prices are quoted does not necessarily indicate the currency that is most relevant for that particular market; for a price quoted in U.S. dollars, for example, it is possible that movements in the effective exchange rate for publications such as the World Economic Outlook for constructing aggregate inflation rates for groups of countries. 
the dollar could systematically induce corresponding changes in the dollar price.

The consequences of choosing an inappropriate denomination may be demonstrated by reference to a simple bivariate model. First, letting $\underline{c}$ denote an index of commodity prices, note that the dollar-denominated Index ( $c^{\prime}$ ) may be converted into GCUs:

(9) $c_{t}-c_{t}^{\prime}-e_{t}$

corresponding to the relationship described for the aggregate CPI in equation ( 8 ). Now suppose that the "true" relationship between commodity and consumer prices, free of exchange rate effects, holds when the data are denominated in GCUs, expressed as

(10) $p_{t}-a+b c_{t}+\varepsilon_{t}$.

Obviously, if one were to estimate, instead of equation (10), a regression in which commodity prices were denominated in dollars (or another currency), a spurious exchange rate effect would be introduced. Perhaps less obviously, a spurious effect would be introduced even if both indexes were denominated in dollars. Suppose one were to estimate

$$
p_{t}^{\prime}-\alpha+\beta c_{t}^{\prime}+\mu_{t}
$$

which is equivalent to

$$
\left(10^{\prime}\right) \quad \mathrm{p}_{t}=\alpha+\beta c_{t}+(\beta-1) \mathrm{e}_{t}+\mu_{t} \text {. }
$$


Unless $\beta=1$, the exchange rate now enters the implicit equation in GCUs, in contrast to equation (10).

In the absence of detailed knowledge about the nature of the individual markets, the best that one can do is to use a broad index of major currencies and to be sure that all data are measured commensurately. Since the aggregate CPI is constructed according to equation (7), it is appropriate to measure commodity prices in GCUs, converting dollar prices by the exchange rate described in equation ( 8 ).

The commodity price index to be used for these tests uses a total of 40 prices, weighted according to $1979-81$ shares in world exports. $1 /$ It is the same index that is used in the World Economic Outlook, as noted in the Introduction. Preliminary tests suggested that similar results (though generally not quite as favorable) would obtain using other weighting methods such as imports or consumption rather than exports. A major decision is whether to include oil prices, since in 1979-81 oil accounted for roughly 50 percent of world exports of primary commodities. The inclusion of oll did somewhat improve the statistical properties in preliminary tests, and it was therefore included in the final index.

\section{Long-run relationships}

The first empirical question to be analyzed is whether there exists a stable long-run relationship between the level of commodity prices and the level of consumer prices. If so, then it may be possible to make quantitative inferences about future CPI inflation from observations of commodity prices. In the absence of a long-run levels relationship,

I/ For a description of prices, see IMF (1986), Appendix II. The export weights are listed in Table 4, below. 
there may still be qualitative linkages between changes in inflation rates in the two data series, but one would want to avoid arguing that any given change in commodity prices would be expected to be followed (eventually) by a specified change in consumer prices.

A very simple heuristic approach to this question is to examine the stationarity of the relative price of commodities. As may be seen from Chart 3, there has been a general downward trend in this relative price; the extent of the drift, however, has not been uniform, and it was starkly interrupted by a sudden and large rise in 1972-73. The hypothesis that the relative commodity price is unbounded in the long run would seem to be a reasonable one to entertain.

One test of this hypothesis is to run augmented Dickey-Fuller regressions for commodity and consumer prices:

$$
\Delta \mathrm{X}_{t}-\beta \mathrm{X}_{t-1}+\Sigma_{i} \gamma_{i} \Delta \mathrm{X}_{t-1}
$$

where the null hypothesis (no stationarity) is that $\beta=0$. Since the data are monthly, without seasonal adjustment, these tests have been run

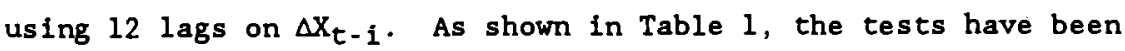
conducted over three sample periods, all ending in 1987 . In addition to the full-sample estimates, regressions have been run for samples beginning in 1972, when commodity prices first began to show substantial fluctuations; and beginning in 1974, after the apparently unique jump in commodity prices that occurred in 1972-73.

In the case of commodity prices, the null hypothesis is rejected, regardless of the sample period. For consumer prices, however, the hypothesis that $\beta-0$ cannot be rejected, although the second differences 


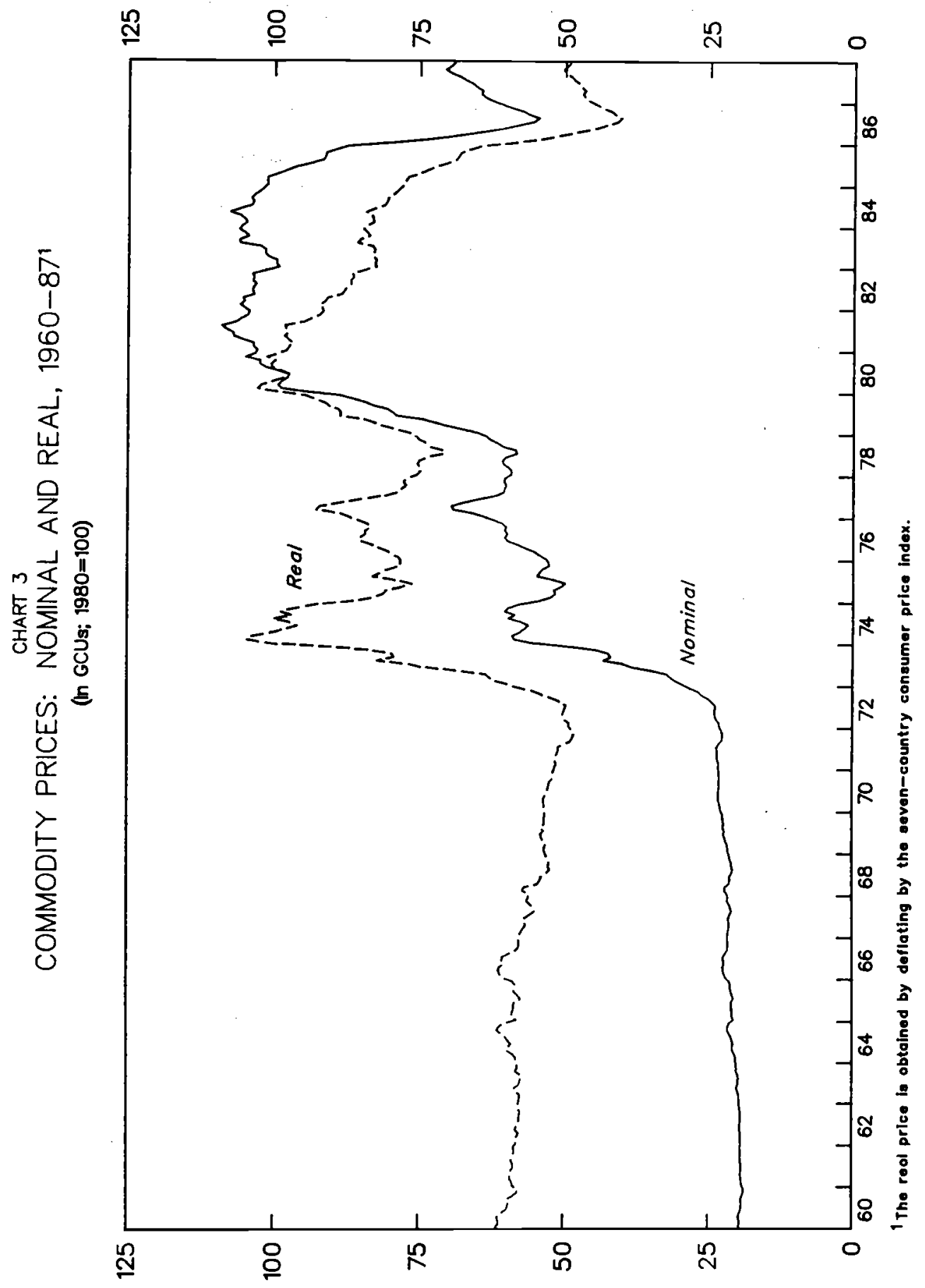


Table 1. Stationarity Tests for Commodity and Consumer Prices 1 /

$\begin{array}{cc}\text { Commodity } & \text { Consumer } \\ \text { Prices } & \text { Prices }\end{array}$

I. Tests for First-Order Stationarity

$1960-87$

$1972-87$

1974-87
$-4.54 * \star$

$-3.37 *$

$-4.49 * *$
$-0.86$

$-0.73$

$-1.37$

II. Tests for Second-Order Stationarity $2 /$

$1960-87$

$-5.82 * *$

$1972-87$

$-3.94 * *$

$1974-87$

$-4.07 * x$

\section{1) The numbers in this table are t-statistics from estimates of} equation (11) over the indicated sample periods using monthly data. The distribution of these statistics is not standard; the 95 percent confidence level for the rejection of nonstationarity ( $*$ ) is approximately 3.17 , and the 99 percent level $(* *)$ is approximately 3.77 . See Engle and Granger (1987).

2) These tests are relevant only where the hypothesis of first-order nonstationarity has not been rejected. 
appear to be stationary. The implication of these tests is that commodity prices are integrated of order 1 , whereas consumer prices are integrated of order 2; that is, the first differences in commodity prices are stationary, whereas only the second differences of consumer prices are stationary. In these circumstances, the two data sets cannot be cointegrated, and the standard cointegration tests are not applicable (see, for example, Granger (1986)). It is thus possible to turn to tests of shorter-run relationships, ignoring the long-run constraints that might otherwise have been imposed by the data. $1 /$.

\section{Short-run relationships}

The next step is to evaluate the relationship between shorter-run movements in commodity and consumer prices. For this purpose, it is helpful to render the data stationary, which may be accomplished simply by taking second differences of the data. As noted above, commodity prices are reasonably stationary in first differences, but second differencing is required to make the full data set stationary. In addition, in order to reduce the importance of seasonal fluctuations, inflation rates have been calculated as 12 -month changes. Thus, the following tests relate to monthly changes in 12 -month inflation rates:

$$
z_{t}=\left(x_{t}-x_{t-1}\right)-\left(x_{t-12}-x_{t-13}\right)
$$

where $x$ is the logarithm of the relevant index and $z$ is the whitened form of the data.

1/ The absence of cointegration in these data was also documented in Durand and Blondal (1988). 


\section{Causality tests}

Table 2 summarizes the results of tests of whether commodity prices "cause," in Granger's sense, consumer prices for the large industrial countries as a group. The null hypothesis is that the lagged values ofcommodity prices contribute nothing to predictions of aggregate CPI inflation, given the predictions from lagged values of the CPI. In addition, tests of reverse causation are also included. In view of the ambiguities associated with the currency denomination of the data, discussed above, the tests have been conducted both with the data expressed in U.S. dollars and with the data denominated in GCUs. Finally, given the rather different behavior of both consumer and commodity prices before and after the early 1970s, the tests have been run over three overlapping samples. The full sample runs from 1960 through 1987; the second sample drops all data before 1972, when commodity prices first displayed a rise in variability; the third begins after the major commodity price inflation of 1972-73.

For the full sample (1960-87), the direction of estimated causation depends entirely on the currency denomination. In terms of U.S. dollars, it appears that consumer prices lead commodity prices; in terms of GCUs, the reverse is true. For the shorter samples, there is no evidence of causation in either direction for non-oil commodity prices. When oil prices are included in the index, and the data are denominated in GCUs, there appears to be causation running from commodity to consumer prices. Given the lack of robustness of the results, it is difficult to draw any firm conclusions from this exercise. Nonetheless, it does seem warranted to conclude that if commodity prices are to serve as a leading indicator 
Table 2: Commodity Prices and Industrial-Country Inflation: Granger Causality Tests $1 /$

\begin{tabular}{|c|c|}
\hline $\begin{array}{l}\text { Commodity } \\
\text { prices } \\
\text { cause } \\
\text { CPI }\end{array}$ & $\begin{array}{c}\text { CPI } \\
\text { causes } \\
\text { commodity } \\
\text { prices }\end{array}$ \\
\hline
\end{tabular}

\begin{tabular}{cc}
\multicolumn{2}{c}{ All Commodities } \\
\hline Commodity & CPI \\
prices & causes \\
cause & commodity \\
CPI & prices
\end{tabular}

With data in U.S. Dollars:

$1960-87$

$1972-87$

$1974-87$

With data in GCUs:

1960-87

1972-87

1974-87

$\begin{array}{ll}-- & \star \star \\ -- & -- \\ -- & --\end{array}$

$\begin{array}{ll}-- & \star \star \\ -- & -- \\ -- & \star\end{array}$

$\star \star$

$\star \star$

*

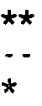

$-$

1 For the test of whether commodity prices Granger-cause the CPI, the CPI has been regressed on 18 lagged monthly values of the commodity price index plus 18 lagged values of itself. For the test of reverse causation, the two series are switched. Industrial-country inflation is measured by the average change in consumer prices for the seven largest countries; the construction of the data is described in the text. All data have been made stationary by taking monthly changes in 12 -month inflation rates. A single asterisk indicates that the null hypothesis--that the aggregate effect of the lagged values of the independent variable is zero--is rejected with 95 percent confidence. A double asterisk indicates rejection of the null with 99 percent confidence. 
of industrial-country inflation, it is preferable to denominate the data in terms of a broad currency basket rather than in terms of U.S. dollars.

\section{Full-sample relationships}

As a fairly simple test of whether commodity prices contribute to predictions of inflation, the changes in the aggregate CPI inflation rate have been regressed on lagged changes in itself plus lagged changes in commodity-price inflation, using polynomial distributed lags (PDLs). I/ The null hypothesis for this test is that the contribution of the PDL on commodity prices does not add to the in-sample explanatory power of the regression.

The baseline regression, omfting commodity prices, is estimated $(1962-87$, monthly data) as

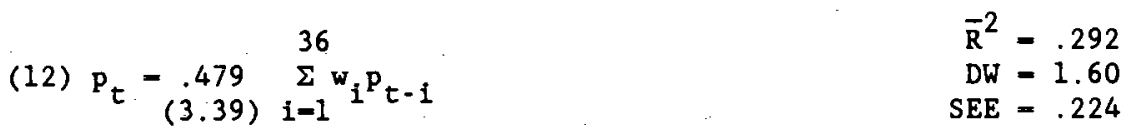

and the expanded regression result is

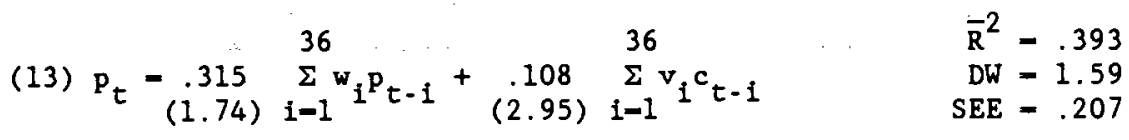

The F statistic for the additional contribution of the commodity price index (c) is 13.8, which implies rejection of the null hypothesis with more than 99 percent confidence.

1) The specific functional form is a 36 -month, 4th-order PDL, constrained to zero at the far end of the distribution. 
An interesting comparison may be made against predictions using an aggregate measure of monetary growth in the large industrial countries. 1/ The data series for money stocks has been extended back only to January 1964; using three-year lags on 12 -month inflation rates and taking moving averages, the regressions for this comparison therefore start in February 1968. For this sample, a regression using only past inflation (as in equation 12 ) has $\bar{R}^{2}-.345$; the addition of a PDL on current and lagged money growth has $\bar{R}^{2}=.361$. The F statistic for the significance of this improvement is 2.5 (significant with 95 percent confidence), compared with 13.8 for commodity prices. It is, of course, possible that other models--allowing for other influences or developing different lag structures--might alter these comparisons. Nonetheless, there is a prima facie case for the value of commodity prices as an inflation predictor.

\section{Post-sample tests}

Table 3 presents information on the out-of-sample predictive ability of commodity prices, with broad-money equations also included for comparison. For this exercise, regressions such as those in equations (12) and (13) were run over a series of six sample periods, starting with 1968-77 and then extending by two years up to 1968-85. In each case, the estimated equations were used to generate dynamic predictions for the aggregate CPI inflation rate over the 24 months following the end of the sample. During the prediction period, commodity price inflation and implicitly denominated in GCUs. 
Table 3. Inflation Predictions, 1976-87 $\underline{1 /}$

(In percent)

$\begin{array}{llllll}1976-77 & 1978-79 & 1980-81 & 1982-83 & 1984-85 & 1986-87\end{array}$

\begin{tabular}{|c|c|c|c|c|c|c|}
\hline Actual Inflation & 7.5 & 9.5 & 10.3 & 4.9 & 3.7 & 2.1 \\
\hline Baseline Prediction & 8.1 & 7.7 & 11.0 & 6.6 & 4.9 & 2.8 \\
\hline Baseline Prediction Error & 0.6 & -1.8 & 0.7 & 1.7 & 1.2 & 0.7 \\
\hline
\end{tabular}

\section{Prodictions Using}

Commodity Prices:

\begin{tabular}{|c|c|c|c|c|c|c|}
\hline Predicted Inflation & 6.6 & 5.5 & 12.0 & 7.5 & 4.9 & 2.7 \\
\hline \multicolumn{7}{|l|}{ Reduction in: } \\
\hline In-Sample Error & 16.8 & 14.6 & 12.2 & 10.5 & 9.5 & 9.5 \\
\hline Prediction Error $\underline{2} /$ & -- & -- & -- & -- & -- & 0.1 \\
\hline RMSE & -- & -- & -- & -- & 2.3 & 60.9 \\
\hline
\end{tabular}

Prediction Using

Broed Money Balances:

Predicted Inflation

7.5

7.5

10.2

7.5

5.3

2.7

Reduction in:

In-Sample Error

2.9

2.2

1.5

1.3

1.0

0.6

Prediction Error $2 /$

0.6

0.6

12.0

96.2

$-$

0.1

RMSE

--

$=$

41.0

1) Post-sample 24-month dynamic predictions of the asgregate CPI from equations as described in the text. The estimation sample is from February 1968 (plus prior lagsed data to December of the year preceding the listed forecast period.

$2 /$ In percentage points. 
broad-money growth were projected on the basis of their own prior history. As shown in the table, three comparisons were made. First, didthe inclusion of commodity prices reduce the standard error of the estimate within the sample period? Second, did the equations that include commodity prices reduce the forecast error for the average inflation rate over the two-year horizon? Third, did they reduce the root mean squared error (RMSE) for the 24 monthly inflation forecasts?

Perhaps the most striking feature of Table 3 is that the RMSE is reduced by the inclusion of commodity prices in only two of the six forecast periods: 1984-85 and 1986-87. Throughout these four years, the prior weakness in commodity prices provided useful information about how rapidly consumer prices would decelerate. In the earlier periods, the predictions are worsened somewhat in comparison with those made only on the basis of the own history of the CPI. The equations using broad money do somewhat better in the earlier periods, but less well in the last two. Overall, the inclusion of neither commodity prices nor broad money could be said to have improved the post-sample inflation forecasts. In contrast, within each sample period, there is a substantial improvement in the fit when commodity prices are included, and only a small improvement when money balances are included. It thus appears that the quantitative linkages between commodity and consumer prices are significant, but are not stable enough to permit one to draw quantitative inferences about the extent to which consumer prices might respond to a given change in commodity prices. 


\section{Empirical estimates of weights}

The tests in Section III took as given the weights assigned to each commodity in the price indexes. The purpose of this section is to examine the feasibility of estimating optimum weights (optimum in the sense of generating the best predictions of the aggregate CPI) for a commodity price index through regression analysis.

\section{a. Estimation of indexes}

Two basic approaches have been used to estimate commodity price indexes on the basis of their relationship with the aggregate CPI. One is to allow the data to determine the weights freely, with all commodity prices as contenders for inclusion in the index. The other involves constraining the data, by eliminating negative weights and, in the final set of estimates, by initially aggregating commodities that have small weights in industrial-country trade or consumption into somewhat broader categories. The second approach was intended to check whether the efficiency of the estimates might be improved by the constraints.

\section{Estimation using all available commodity price data}

The objective of the first approach is to allow the maximum freedom for the data to "speak" in determining the "best" weights for commodities for the purpose of predicting CPI inflation. This approach uses the prices that are incorporated into the available IMF commodity price indexes, plus the prices of gold and petroleum, in an unconstrained regression framework. There are some 30 years of monthly observations on the 40 commodity price series, extending from January 1958 through September 1987. With a forecast horizon chosen to run from 1 to 36 months, the problem is to devise a procedure that narrows quickly to the most 
important explanatory variables over different forecast horizons with a minimum of loss in efficiency in utilizing the information in the data. The procedure that was employed to estimate "optimum" indexes was as follows. First, the aggregate CPI and all 40 series, expressed as logarithms of GCU-denominated indexes, were transformed by taking the first differences of their 12 -month differences (i.e., changes in inflation rates). Second, the forty principal components were extracted from the data matrix of the transformed commodity price data, to produce orthogonal regressors. Third, a multiple regression was estimated over the period February 1962 to December 1982 with the transformed CPI as the dependent variable and the forty principal components as independent variables (with the constant suppressed) separately at each lag length from 1 to 36 months. The termination of the sample at the end of 1982 was chosen so as to leave a reasonably long post-sample period for testing the stability of the results.

These regression results were used to select significant principal components for the remaining analysis. Two selection criteria were used to narrow the set of principal components. The first was to rank them by average absolute t-ratio across lags. The second was to select principal components with coefficients that were significant at the 1 percent level at at least 4 different lags, of which at least one was longer than 12 months. The second criterion yielded eight principal components, of which six coincided with those in the highest eight on the average absolute t-ratio criterion. Thus the two criteria together yielded a list of ten candidate principal components for the next stage. 
Next, a regression was estimated with the transformed CPI as the dependent variable, and fourth-order PDLs with length 36 months (constrained to zero at the far end only) on the candidate principal components as independent variables along with a similar PDL on the lagged transformed CPI. This regression (over the 1962-82 period) had an adjusted $R^{2}$ of .57 , compared with .32 for a regression of the transformed CPI only on its own lags. Each of the ten selected principal components contributed significantly to this regression. Finally, the coefficient on the weighted (and normalized) lag distribution on each principal component was taken as an estimate of the contribution of that component to the index being derived.

The lag distributions on the ten principal components in the final regression differ in length and shape. Therefore, when the implied weights on the commodity prices are retrieved, a weighting matrix is obtained, which in principle would have a different set of weights for each lag length. Thus the distributed lag coefficients on the final principal components equation could be used to estimate a different set of weights for the commodity prices at each forecast horizon, reflecting differences in the information in the various commodity prices for explaining aggregate CPI inflation at different forecast horizons. This step was not taken at this stage. Instead, a single set of weights was calculated, reflecting the average information in the commodity price series across forecast horizons. These are the weights shown in the first column of Table 4.

The most notable feature of the weights in the unconstrained index is that about half of the commodities have negative weights. In 
Table 4. Econometrically Estimated Weights for Commodity Price Indexes $1 /$

(In percent)

\begin{tabular}{|c|c|c|c|c|}
\hline Commodity $2 /$ & Unconstrained & $\begin{array}{c}\text { Eliminating } \\
\text { Negative } \\
\text { Weights }\end{array}$ & $\begin{array}{l}\text { Using } \\
\text { Prior } \\
\text { Aggregation }\end{array}$ & $\begin{array}{l}\text { Memorandum: } \\
\text { World } \\
\text { Export } \\
\text { Weights } 3 /\end{array}$ \\
\hline $\begin{array}{l}\text { Cereal } \\
\text { Wheat } \\
\text { Maize } \\
\text { Rice }\end{array}$ & $\begin{array}{r}-21.9 \\
-4.8 \\
60.8 \\
-77.8\end{array}$ & $\begin{array}{c}\frac{7.3}{-\cdots} \\
7.3 \\
-.\end{array}$ & $\begin{array}{r}10.3 \\
5.0 \\
3.7 \\
1.6\end{array}$ & $\begin{array}{r}10.6 \\
5.1 \\
3.8 \\
1.6\end{array}$ \\
\hline $\begin{array}{c}\text { Vegetables } \\
\text { Soybeans } \\
\text { Other }\end{array}$ & $\begin{array}{r}\frac{-4.7}{16.0} \\
-20.6\end{array}$ & $\begin{array}{r}\frac{12.1}{10.9} \\
1.2\end{array}$ & $\begin{array}{l}\frac{4.9}{3.9} \\
1.0\end{array}$ & $\begin{array}{l}\frac{5.7}{4.5} \\
1.2\end{array}$ \\
\hline $\begin{array}{l}\text { Meat } \\
\text { Beef } \\
\text { Lamb }\end{array}$ & $\begin{array}{r}-6.3 \\
-38.7 \\
32.4\end{array}$ & $\frac{3.9}{3.9}$ & $\begin{array}{l}\cdots \\
\cdots \\
-\end{array}$ & $\begin{array}{l}\frac{3.3}{2.8} \\
0.5\end{array}$ \\
\hline Sugar & 27.2 & $\underline{5.2}$ & 1.0 & 1,6 \\
\hline Bananas & -9.7 & -- & $\cdots$ & $\underline{0.4}$ \\
\hline $\begin{array}{l}\text { Beverages } \\
\text { Coffee } \\
\text { Cocoa } \\
\text { Tea }\end{array}$ & $\begin{array}{r}\frac{38.2}{-19.7} \\
42.5 \\
15.5\end{array}$ & $\begin{array}{r}\frac{19.0}{12.1} \\
5.1 \\
1.9\end{array}$ & $\begin{array}{l}\cdots \\
\cdots \\
\cdots\end{array}$ & $\begin{array}{l}\frac{6.0}{3.8} \\
1.6 \\
0.6\end{array}$ \\
\hline $\begin{array}{l}\text { Agricultural } \\
\text { new materials } \\
\text { Timber } \\
\text { Cotton } \\
\text { Wool } \\
\text { Rubber } \\
\text { Tobacco } \\
\text { Other }\end{array}$ & $\begin{array}{r}59.0 \\
60.0 \\
-88.7 \\
-39.1 \\
25.9 \\
54.5 \\
46.4\end{array}$ & $\begin{array}{r}\frac{26.3}{7.2} \\
-. \\
\quad . \\
3.1 \\
6.5 \\
9.4\end{array}$ & $\begin{array}{r}52.2 \\
15.6 \\
\ldots \\
\ldots \\
11.9 \\
24.7 \\
\ldots\end{array}$ & $\begin{array}{l}\frac{12.0}{5.4} \\
2.0 \\
1.2 \\
1.3 \\
1.3 \\
0.7\end{array}$ \\
\hline $\begin{array}{l}\text { Metals } \\
\text { Copper } \\
\text { Aluminum } \\
\text { Gold } \\
\text { Iron ore } \\
\text { Other }\end{array}$ & $\begin{array}{r}\frac{-7.6}{24.3} \\
-0.5 \\
5.0 \\
62.6 \\
-99.1\end{array}$ & $\begin{array}{r}\frac{23.1}{2.9} \\
. . \\
0.6 \\
7.6 \\
12.1\end{array}$ & $\begin{array}{l}\frac{2.1}{0.4} \\
0.3 \\
0.5 \\
0.3 \\
0.6\end{array}$ & $\begin{array}{l}\frac{14.9}{3.0} \\
2.3 \\
3.7 \\
2.1 \\
3.8\end{array}$ \\
\hline Petroleum & 25.8 & 3.1 & $\underline{29.4}$ & $\underline{45.5}$ \\
\hline Total & 100.0 & 100.0 & 100.0 & 100.0 \\
\hline
\end{tabular}

1) Detail may not add to totals, owing to rounding.

2) Several of the listed conmodities are divided into two or more components in the full data set. When negative weights were reset to zero for the second index, the calculations were made at that disaggregated level.

3) Based on 1979-81 data. Source: IMF, Commodities Division. 
particular, within most groups, some commodities have positive and some negative weights. The reason for the negative weights is not that a rise in the price of a particular commodity, by itself, would be expected to lead to a fall in consumer prices; it is rather that the regression essentially computes the weights for an optimal portfolio of commodity prices that minimizes the residual error vis-a-vis the CPI. This procedure assigns negative weights to some prices that have positive covariance with the others. Small changes in specification could easily reverse the signs on individual commodities. The individual weights therefore should not be assigned much intrinsic value.

The time path of this index is shown in the far left panel of Chart 4. It is apparent that this is a much more volatile index than the others. In 1974 it even took on negative values, reflecting rapid increases in prices--especially certain metals--that have negative weights in the index. Nonetheless, a moving average of this index would have a time profile reasonably similar to those of the other indexes shown in the chart.

A regression of the transformed aggregate CPI on its own history plus a 36 -month PDL on this first index yielded an adjusted $\mathrm{R}^{2}$ of .32 . The reduction from .57 is a measure of the cost of time aggregation into a single index; in fact, it may be seen that most of the improvement over equation (12) has been lost through time aggregation. The out-of-sample performance of this index is examined in the next subsection. 


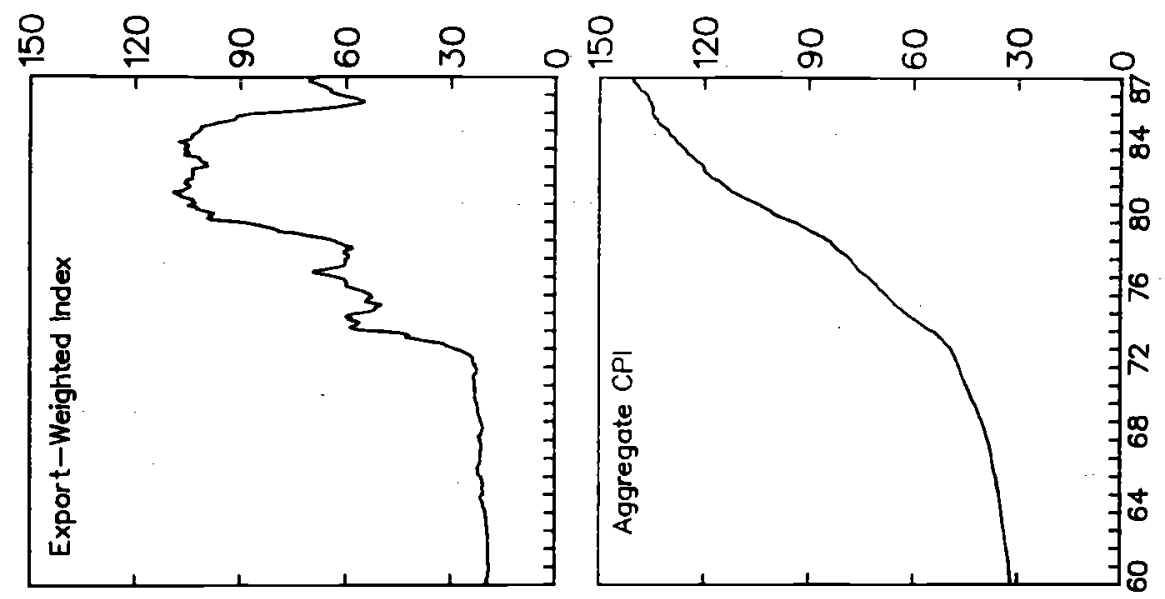

5 $\begin{array}{cc}0 & 1 \\ 0 & 0 \\ \times & 0 \\ \omega & 0\end{array}$ $w$ I $\omega \frac{U}{\pi}$ 山文。 山ᄄ 崖岕 ○氙 证 40 忩是
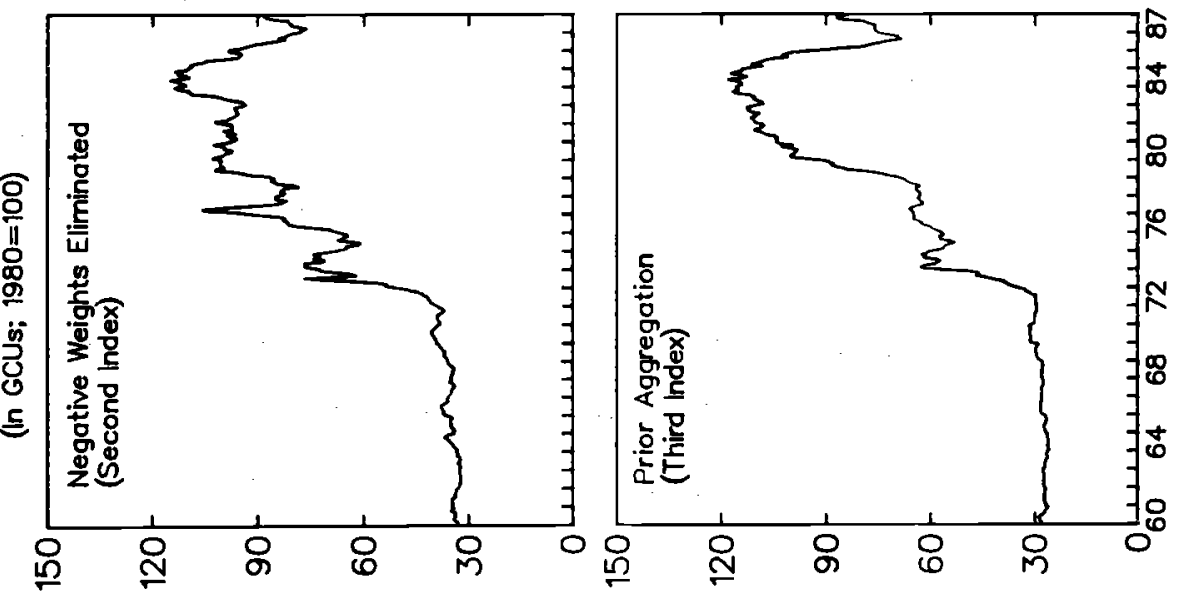

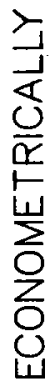

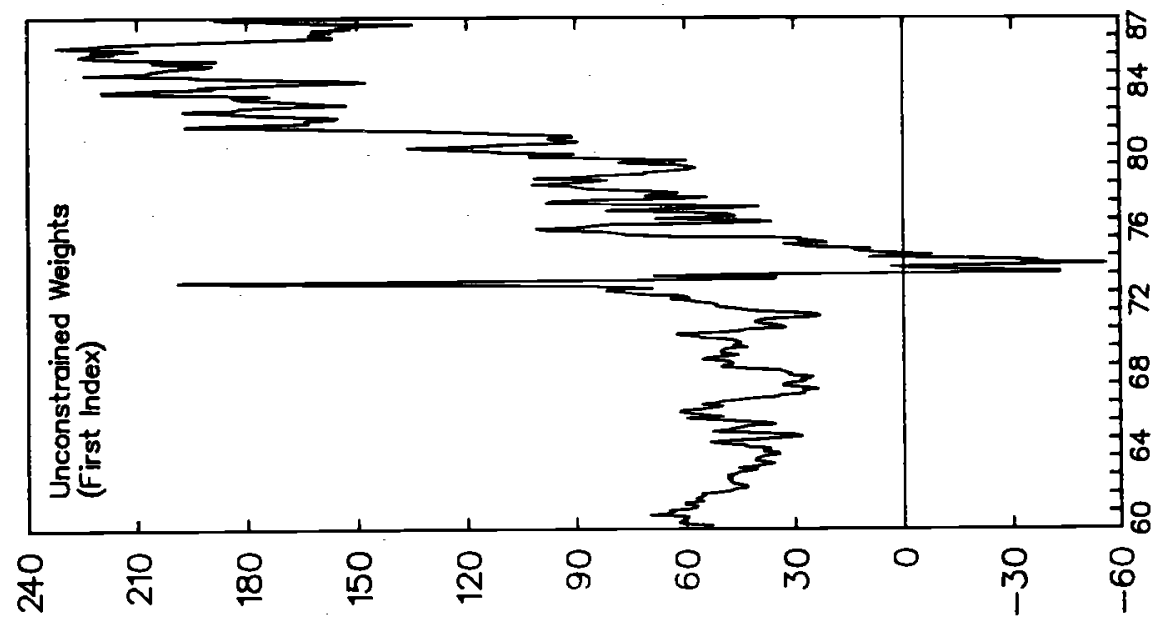




\section{Estimation subject to constraints}

The second index was derived from the first by simply eliminating all of the commodities whose prices had negative coefficients in the first index. The weights for this index are shown in the second column of Table 4. As may be seen by comparing these weights with the export weights in the last column of the table, and by examining the movements in the index as shown in Chart 4, this index looks more like a conventional price index than does the unconstrained version.

A regression of the transformed aggregate CPI on itself lagged, plus a PDL on the transformed version of this second index, yielded an adjusted $\mathrm{R}^{2}$ of .33 , which is slightly higher than that for the first index but still well below the performance of the conventional export-weighted index (equation 13, above).

The third index (third column of Table 4 and lower left panel of Chart 4) was derived by a procedure that differed in two major respects from that used for the first two indexes. First, most of the prices in the original set of forty were aggregated into broader categories, in order to reduce the amount of detailed information required for the estimation process and to eliminate the possibility that a commodity with relatively little importance in trade or consumption might have a large weight in the estimated index. This aggregation procedure, using world export weights, produced six aggregates (cereals, vegetable oils, 
beverages, meat, metals, and fibers) and five single commodities (sugar, petroleum, rubber, tobacco, and timber). I/

When these 11 prices were converted into stationary series by taking changes in 12 -month rates of change, there was very little multicollinearity in the data matrix. Therefore, it was decided to compute the regressions using these transformed prices rather than their principal components. Thus the second stage of the procedure was to regress the transformed aggregate CPI on PDLs of the 11 transformed price series, plus the PDL on its own lagged values. $2 /$ That regression yielded an adjusted $R^{2}$ of .52 , compared with .57 for the unconstrained estimation of the first index. As before, the coefficients on the sums of the lag distributions from this regression were normalized to sum to unity and were used as the weights for the third index. The time profile for this index (Chart 4) is quite similar to that of the export-weighted index, although there are periods when they move independently. A regression using a PDL on this index had an adjusted $R^{2}$ of .43 ; this is the best insample result for any of the four indexes.

1 The prices of bananas, hides, jute, and sisal, which did not fit neatly into the sub-aggregates and which had a small weight in both consumption and trade, were elimated from this data set. The price of sugar for this exercise is a weighted average of the three prices in the full data set (a free market price and the U.S. and European Community import prices).

2) In order to further simplify the procedure, the lag lengths in this regression were shortened to 12 months (except for petroleum, whose effect ran out to 24 months), the polynomials were constrained to third rather than fourth degree, and the end-point constraint was dropped. 


\section{b. Evaluation of the estimated indexes}

The properties of a leading indicator are, of course, not well defined by how well they fit within the sample period. This subsection therefore examines the post-sample properties of the estimated indexes. These properties are summarized in Table 5, which may be compared with the results presented above in Table 3.

As with the full-sample results, it may be seen that the third index does much better than the other two estimated indexes, and a little better than the export-welghted index, in terms of reducing the standard error of the estimate for in-sample CPI predictions. Post-sample, however, the unconstrained index does quite a bit better: the average prediction error is reduced in three of the six periods, and the RMSE is reduced in four of six cases.

The apparently poor overall quantitative performance of commodity prices as additional inflation predictors is attributable in part to the difficulty of forecasting commodity prices during the forecast period. When actual commodity prices are used in the post-sample period, the prediction errors drop sharply. The use of a 24-month dynamic forecast period is a harsh standard, and the choice is to some extent arbitrary. Given the strong in-sample performance--especially for the third estimate index as well as for the export-weighted index--it is likely that better results would be obtained for shorter horizons.

Qualitative relationships may be as important as quantitative ones if commodity prices are to serve as a leading indicator. That is, one may be at least as interested in predicting turning points in CPI 
Table 5. Inflation Predictions Using Estimated Commodity Price Indexes, 1976-87.1/

(In percent)

\begin{tabular}{|c|c|c|c|c|c|c|}
\hline & $1976-77$ & $1978-79$ & $1980-81$ & $1982-83$ & $1984-85$ & $1986-8$ \\
\hline Actual Inflation & 7.5 & 9.5 & 10.3 & 4.9 & 3.7 & 2.1 \\
\hline Baseline Prediction & 8.1 & 7.7 & 11.0 & 6.6 & 4.9 & 2.8 \\
\hline Baseline Prediction Error & 0.6 & -1.8 & 0.7 & 1.7 & 1.2 & 0.7 \\
\hline
\end{tabular}

Predictions Using First

(Unconstrained) Index:

Predicted Inflation

Reduction in:

In-Sample Error

Prediction Error

RMSE

Prediction Using Second

(Positive-Weisht) Index:

Predicted Inflation

Reduction in:

In-Sample Error

Prediction Error

RMSE

Prediction Using Third

(Prior-Aggregation) Index:

Predicted Inflation

Reduction in:

In-Sample Error

Prediction Error

RHSE
7.9

8. 4

11.0

6. 3

4.9

3. 3

4. 8

5.0

5. 3

4.3

4.7

4. 3

0.2

0.7

32.8

27.0

0.3

21. 1

19. 0
6.0

11.2

7.3

6.4

4. 3

8. 0

8. 5

6. 5

6.5

6.3

5. 3

$-$

--

--

--

--

$-$

3.8

6.2

11.8

7.5

3.8

3.2

18.2

16.4

15.2

14.7

12.5

12.6

-. -.

--
$-$
1.1

94.6

12.7

1) Post-sample 24-month dynamic predictions of the agsregate CPI from equations as described in the text. The estimation sample is from February 1962 (plus prior lagsed data to December of the year preceding the listed forecast period. 
inflation as in predicting the value of the future inflation rate. It was already noted (see Chart 1) that there is an observed tendency for inflation in the export-weighted commodity price index to display cyclical patterns that are similar to those of the aggregate CPI inflation (though with differing amplitudes) and that frequently lead CPI turning points. This tendency is examined more closely in Table 6 .

The first three columns of Table 6 list the turning points in the aggregate CPI inflation (denominated in GCUs) since the beginning of 1970. 1/ These turning points are defined by a shift in direction that $i$ sustained for at least three months. For a peak, it is also required tha it exceed the previous trough by at least 75 basis points; troughs must b at least 50 basis points below the previous peak. These requirements are obviously rather arbitrary, but they do capture the major turns in CPI inflation, taking account of the general upward drift in the data.

The remaining columns of Table 6 indicate the lead times that one would have obtained from various commodity price indexes, or from monetary growth. These lead times are shorter than the actual lead times usually by three or four months, in order to take account of the need for identifying a turning point. For example, when commodity price inflation reaches a trough, one cannot immediately identify it as such; only after it has risen for two or three months can one know that a trough has occurred. These turning points are defined as for the CPI, except that the required magnitudes are larger and are symmetric, reflecting the displayed very little cyclical behavior during that decade. 
Table 6. Prediction of Turning Points in Aggregate CPI Inflation

Turning Points in Aggregate CPI Inflation

\begin{tabular}{llc}
\hline & Peak or & Inflation \\
Date & Trough & Rate \\
\hline
\end{tabular}

\begin{tabular}{|c|c|c|c|c|c|c|c|}
\hline Feb. 1970 & $\mathbf{P}$ & 6.0 & -- & 4 & $\cdots$ & $-\cdot$ & 1 \\
\hline June 1972 & $\mathrm{~T}$ & 3.9 & $-\cdot$ & 6 & 6 & 4 & - - \\
\hline Nov. 1974 & $\mathbf{P}$ & 13.7 & 7 & - & $0 x$ & 7 & - \\
\hline July 1976 & $\mathrm{~T}$ & 7.1 & 6 & $\cdots$ & $5 x$ & 6 & $\ldots$ \\
\hline June 1977 & $\mathbf{P}$ & 8.2 & $1 \mathrm{x}$ & 15 & 2 & 2 & - - \\
\hline April 1978 & $\mathrm{~T}$ & 6.4 & $\cdots$ & $\cdots$ & $\cdots$ & - & 7 \\
\hline April 1980 & $\mathbf{P}$ & 12.1 & 0 & 16 & 6 & $\cdots$ & - \\
\hline Dec. 1986 & $\mathrm{~T}$ & 1.0 & $2 \mathrm{x}$ & - & $11 x$ & $1 \mathrm{x}$ & - \\
\hline Nov. 1987 & $\mathbf{P}$ & 3.1 & 0 & $\ldots$ & $\cdots$ & $\ldots$ & - - \\
\hline
\end{tabular}

1) $x$ indicates that a false signal preceded the correct one.

- Indicates that (a) the index was pointing in the wrong direction at the time of the turning point in the CPI or (b) that the index called the turning point more than 18 months in advance or before the preceding turning point. 
different patterns in the data. 1/ A lead time of zero months is treated as a successful prediction, because the commodity price data are available a few weeks earlier than the CPI data.

The main conclusion to be drawn from Table 6 is that the commodity price indexes--with the exception of the first (unconstrained) estimated index--are reasonably successful predictors of turning points. The conventional export-weighted index predicted six of the nine turning points, as did the second estimated index. These indexes gave from one t three false signals over the 18 -year period. The third estimated index predicted five turns, while the first predicted four. $\underline{2}$ In contrast, growth in the aggregate stock of money predicted only two of the nine turning points in the aggregate CPI.

\section{v. Conclusions}

This paper has argued that commodity prices might serve as a useful leading indicator of inflation, based on the relative importance of flexible auction markets for the determination of these prices. They thu: may have a tendency to respond relatively quickly, especially in response to monetary disturbances. This conclusion holds regardless of whether primary commodities serve mainly as final goods or as industrial inputs.

1) For the first estimated index, which is highly volatile, the required swing is 50 percentage points. For the other commodity price indexes, the required swing is 5 percentage points. For broad money, the requirement is the same as that for the CPI.

2) The results for the estimated indexes are hypothetical and illustrative, because the indexes were constructed using data through 1982 and so could not have been used to predict the earlier turning point. 
Empirical evaluation of conventional trade-weighted commodity price indexes leads to several conclusions. First, commodity and consumer prices are not co-integrated; the hypothesis that the relative price of primary commodities is bounded, or that there is a reliable long-run relationship between the level of commodity prices and the level of consumer prices, may be rejected. Second, there is a tendency for changes in commodity prices to lead those in consumer prices, at least when the data are denominated in a broad index of major-country currencies. When the data are denominated in U.S. dollars, consumer prices appear to lead commodity prices. This conclusion underscores the importance of making appropriate allowances for exchange rate changes in analyzing these relationships. Third, although the inclusion of commodity prices significantly improves the in-sample fit of regressions of an aggregate (multi-country) consumer price index, the results may not be sufficiently stable to improve post-sample forecasts. The prediction record, however, improves in the most recent period.

Estimation of alternative commodity-price indexes, in which the weights are chosen so as to minimize the residual variance in aggregate inflation regressions, was not fully successful. The derived indexes do track the behavior of the aggregate CPI reasonably well in-sample. On the other hand, the weights are not robust with respect to changes in the methodology, and the indexes work only moderately well in post-sample predictions. Overall, the estimated indexes do not appear to offer significant advantages over the conventional export-weighted index. 
The bottom line is that commodity prices do have a useful role to play in this context, but one must be careful to interpret the relationships correctly. The ratio of consumer to commodity price movements changes over time, and the relative price of commodities undergoes long sustained swings; nonetheless, the qualitative linkages are quite evident in the data. Perhaps most importantly, turning points in commodity-price inflation frequently precede turning points in consumer-price inflation for the large industrial countries as a group. 


\section{References}

Angell, Wayne D., "A Commodity Price Guide to Monetary Aggregate

Targeting;" paper prepared for Lehrman Institute, December 10, 1987.

Bosworth, Barry P., and Robert Z. Lawrence, Commodity Prices and the New

Inflation, The Brookings Institution (Washington), 1982 .

Dornbusch, Rudiger, "Expectations and Exchange Rate Dynamics," Journal of

Political Economy, Vol. 84 (1976), pp. 1161-76.

Durand, Martine and Sveinbjörn Blöndal, "Are Commodity Prices Leading

Indicators of OECD Prices?" OECD Department of Economics and

Statistics, Working Paper No. 49 (February 1988).

Engle, Robert F. and C.W.J. Granger, "Co-Integration and Error

Correction: Representation, Estimation, and Testing,"

Econometrica, Vol. 55 (March 1987), pp. 251-76.

Frankel, Jeffrey A., "Expectations and Commodity Price Dynamics: The Overshooting Model," American Journal of Agricultural Economics. Vol. 68 (May 1986), pp. 344-48.

Frenkel, Jacob A. and Carlos A. Rodriguez, "Exchange Rate Dynamics and the Overshooting Hypothesis," Staff Papers, International Monetary Fund (Washington) Vol. 29, No. 1 (March 1982), pp. 1-30.

Granger, C.W.J., "Developments in the Study of Cointegrated Economic Variables," oxford Bulletin of economics and Statistics, Vol. 48 (August 1986), pp. 213-28.

Hall, Robert E. (1982), Inflation: Causes and Effects, (Chicago: The University of Chicago Press), 1982. 
Ha11, Robert E. (1987), "Cholce of Indicators for Monetary Policy," testimony before the Subcommittee on Domestic Monetary Policy and the Subcommittee on International Finance, Trade, and Monetary Policy, U.S. House Committee on Banking, Finance, and Urban Affairs, November $17,1987$.

International Monetary Fund (1986), Primary Commodities: Market Developments and Outlook (Washington: IMF). May 1986.

International Monetary Fund (1988), World Economic Outlook: A Survey by the Staff of the International Monetary Fund (Washington: IMF), Apri1 1988 .

Klein, Philip A., "Leading Indicators of Inflation in Market Economies," International Journal of Forecasting, Vol. 2 (1986), pp. 403-12.

Roth, Howard L., "Leading Indicators of Inflation," in Kajal Lahiri and Geoffrey Moore (eds.) Leading Economic Indicators (Cambridge University Press, forthcoming). 